\title{
Integration of Cement and Hydrogen Industries for Canada's Climate Plan: Case Study
}

\author{
Rami S. El-Emam, Neha Bagria, Kamiel S. Gabriel \\ Ontario Tech University \\ Oshawa, ON, Canada \\ Rami.Elemam@ontariotechu.ca; Neha.Bagria@ontariotechu.net; Kamiel.Gabriel@ontariotechu.ca
}

\begin{abstract}
In December 2020, Canada released its national strengthened climate change plan with focus on cutting energy waste and pollution towards building clean industrial advantage. Two weeks later, the national hydrogen strategy was announced urging all involved stakeholders to delve into the deployment of large-scale clean hydrogen technologies. Ontario, Canada's largest economy and leading manufacturing province, releases its provincial hydrogen strategy and roadmap later this year. This paper represents a viable solution for reducing $\mathrm{CO} 2$ emissions from large industry pollutants by integrating our innovative copper chlorine $(\mathrm{Cu}-\mathrm{Cl})$ thermochemical hydrogen production technology with the energy intensive and polluting industry of cement manufacturing. The paper highlights the nexus between the production process of two valuable commodities, namely cement and Hydrogen, and the role their integration introduces for increased energy efficiency and reduction of greenhouse gas emissions. In addition, as the kiln processes of cement manufacturing consume approximately $99 \%$ of total thermal energy use, the paper proposes different scenarios involving the use of hydrogen to partially meet the kiln's heat demand. The scenarios show the possibility of achieving over $43 \%$ reduction in $\mathrm{CO}_{2}$ emissions compared to coal-based kiln production, along with reduced recurring cost for operating the kiln. On-site large-scale hydrogen production, mixed with NG was, found to be financially viable and environmentally advantageous.
\end{abstract}

Keywords: hydrogen, cement, $\mathrm{Cu}-\mathrm{Cl}$ thermochemical cycle

\section{Introduction}

Cement production process has a significant pollution footprint. It is an energy intensive process that utilizes extensive amount of heat to process raw materials and converts them into cement. It is estimated that cement production contributes more than $8 \%$ of the global $\mathrm{CO}_{2}$ emissions [1]. Close to $40 \%$ of these emissions is released during the direct combustion of fuel to drive the clinker production process. The rest is produced from limestone decarbonation reaction to produce the primary component of clinker, calcium oxide. Other indirect $\mathrm{CO}_{2}$ emissions are the result of electric power consumption and transportation. This contributes another $10 \%$ of the overall emissions from the plant. To be able to meet the Paris Agreement goals on limiting the rise in global temperature to below $2^{\circ} \mathrm{C}$, emissions from cement industry need to be reduced $16 \%$ by 2030 [2]. Efficient and optimized use of cement in concrete mixes, maximizing design life of infrastructure, buildings, and other constructions would allow us to reach this goal sooner. Other strategies to reduce cement demand and to achieve the necessary reduction in emissions include improving plant's thermal energy efficiency, switching to alternative and clean fuels, reducing and employing sustainable substitutions of clinker in cement, as well as incorporating carbon capture and storage (CCS) to the production process. Most cement-producing countries use coal and other fossil fuels for powering their cement manufacturing process. Meanwhile, several countries, especially in the European Union, have been steadily increasing the use of alternative low-carbon fuels to drive their cement manufacturing plants including the use of biomass and waste material.

This paper provides a case study for the potential of integrating hydrogen and cement industries to achieve higher efficiency and reduce emissions. The proposed method uses the innovative $\mathrm{Cu}-\mathrm{Cl}$ thermochemical water splitting technology for clean hydrogen production to recover waste heat from cement plant. The paper also discusses alternative routes for greening one of Canada's largest producer of cement clinker in Ontario. Partial substitution of the plant fuel demand using cleaner fuels is proposed. The environmental and economic impact in two different scenarios (scenario II and III) are provided in comparative assessment with respect to a base scenario (scenario I). 


\section{Nexus between Hydrogen and Cement Industries}

The availability of large amount of waste heat of relatively high quality at cement plants opens the door for opportunities to integrate a thermal hydrogen plant for on-site hydrogen production. The thermochemical CopperChlorine $(\mathrm{Cu}-\mathrm{Cl})$ hydrogen production technology (Fig. 1), developed at Ontario Tech University, is one for promising routes that allows for employing the recovered waste heart from industries such as cement and steel manufacturing process, to feed the energy demand of the hydrogen production process. In the $\mathrm{Cu}-\mathrm{Cl}$ hydrogen technology, a loop of three main reactions is maintained where Cupric Chloride $(\mathrm{CuCl} 2)$ salt reacts with steam at around $375^{\circ} \mathrm{C}$ in the hydrolysis step (Eq. (1)) to form copper oxychloride $(\mathrm{CuOCuCl} 2)$ and hydrochloric acid $(\mathrm{HCl})$. The $\mathrm{CuOCuCl} 2$ is heated to its melting temperature at around $500^{\circ} \mathrm{C}$ in the thermolysis step (Eq. (2)) releasing oxygen gas and forming Cuprous Chloride $(\mathrm{CuCl})$ salt, which reacts with the previously produced stream of $\mathrm{HCl}$ in an electrochemical cell (Eq. (3)) forming hydrogen gas while the liberated Chlorine binds with $\mathrm{CuCl}$ forming $\mathrm{CuCl} 2$. The formed salt is recycled back to the first step of the cycle.

$$
\begin{gathered}
2 \mathrm{CuCl}_{2(\mathrm{~s})}+\mathrm{H}_{2} \mathrm{O}_{(\mathrm{g})} \rightarrow \mathrm{Cu}_{2} \mathrm{OCl}_{2(\mathrm{~s})}+2 \mathrm{HCl}_{(\mathrm{g})} \\
2 \mathrm{Cu}_{2} \mathrm{OCl}_{2(\mathrm{~s})} \rightarrow 4 \mathrm{CuCl}_{(\mathrm{l})}+\mathrm{O}_{2(\mathrm{~g})} \\
2 \mathrm{CuCl}_{(\mathrm{aq})}+2 \mathrm{HCl}_{(\mathrm{aq})} \rightarrow \mathrm{H}_{2(\mathrm{~g})}+2 \mathrm{CuCl}_{2(\mathrm{aq})}
\end{gathered}
$$

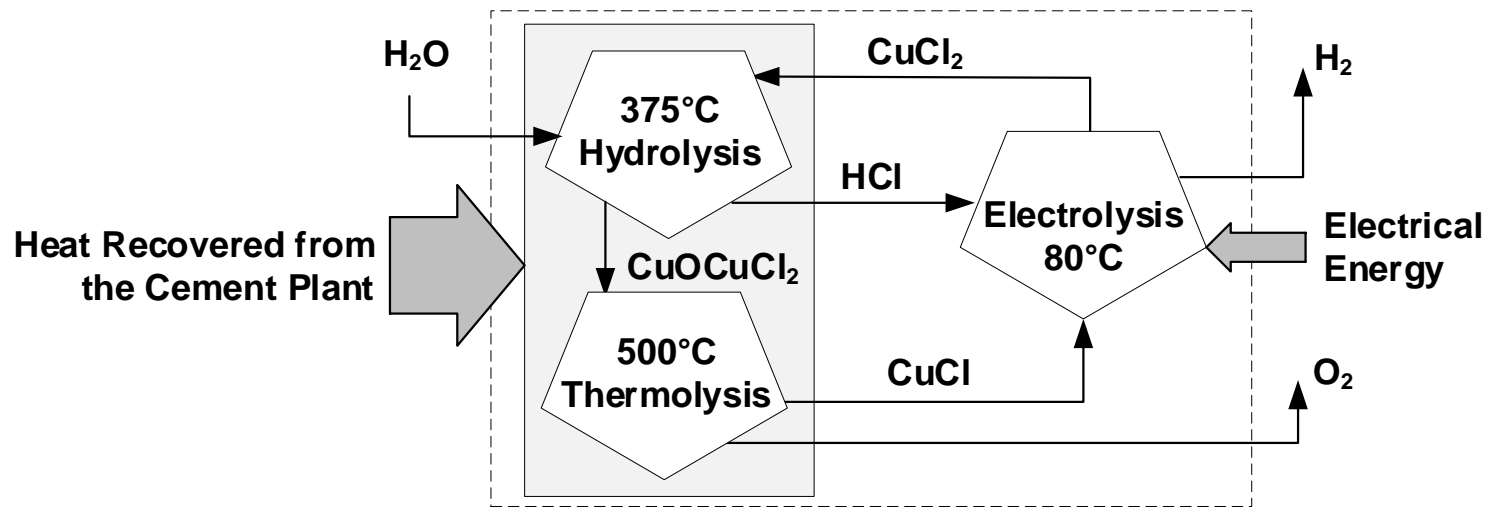

Fig.1: a simplified schematic of the $\mathrm{Cu}-\mathrm{Cl}$ cycle

With the $\mathrm{Cu}-\mathrm{Cl}$ technology requiring steady-state continuous operation, it fits well for integration with cement plants which are in general operating continuously throughout the year. Existence of on-site hydrogen plant is beneficial to the cement manufacturing process in many aspects. On-side produced hydrogen can be mixed with natural gas along with the other fuel mixture of the cement plant. This will result in reducing $\mathrm{CO}_{2}$ emission from the plant. Hydrogen can be also utilized for Power to Grid (P2G) application where hydrogen can be placed directly into the natural gas grid, for subsequent usage in other industries or in the transportation or mobility sector. It also can be stored in a hydrogen buffer to be converted into electricity later or converted into methane, ammonia, or methanol. With regards to using produced hydrogen for $\mathrm{P} 2 \mathrm{G}, \mathrm{Cu}-\mathrm{Cl}$ technology can be more advantageous over electricity-powered water-splitting technologies. Using electricity to produce hydrogen via conventional electrolysis and then compress it to be injected into the natural gas infrastructure is about $25-30 \%$ efficient at best. Another benefit of a co-located hydrogen plant at the cement plant is the production of $8 \mathrm{~kg}$ of oxygen per $1 \mathrm{~kg}$ hydrogen. Along with the potential of selling the pure produced oxygen for industrial or medical purposes, there is value added benefit in using oxygen for oxyfuel enhancement in the cement manufacturing process. Oxygen can be mixed with the combustion air provided to the kiln burners.

\section{General Assumptions and Definition of Scenarios}

In this case study, it is assumed that the specific heat consumption of the kiln is 2.25 GJ per tonne of produced clinker [3-5] with heat-delivery efficiency of 65\%, assumed based on the data from the literature [3-7]. A hypothetical 
scenario assuming total thermal load to the kiln is provided using bituminous $A$ coal is taken as a base case (scenario I). Natural gas enriched with hydrogen is proposed to cover half of the thermal energy demand of the kiln. Another case considered only natural gas to provide the same percentage of heat demand and was analysed to determine the impact of enriching the natural gas stream with hydrogen. Hydrogen is produced on-site using the $\mathrm{Cu}-\mathrm{Cl}$ thermochemical hydrogen production technology utilizing the waste heat from the downcomer side of the hot exhaust of the cement kiln. The $100 \%$ coal fuelled scenario, the 50\% coal with 50\% natural gas scenario, and the 50\% coal with 50\% hydrogen-enriched natural gas scenario are mentioned hereafter as Scenario I, II and III, respectively.

The infrastructure requirements were estimated for the proposed retrofitting the plant with natural gas pipeline (utilized in Scenarios II and III), and the hydrogen and gas-mix pipeline of Scenario III. Based on a safe flow velocity, pipe specifications were defined, including inner and outer diameters, and pressure and velocity values for safe operating conditions. The pipe size was determined by selecting next largest size above the minimum diameter estimation.

In scenario III, the capital cost of the $\mathrm{Cu}-\mathrm{Cl}$ hydrogen plant with capacity of 10 tonnes/day was estimated to be $\$ 13.4$ million considering cumulative inflation of $13.39 \%$ since 2014, the date of data reported at El-Emam and Khamis [8].

\section{Results and Discussion}

The analysis of scenario I, where coal is utilized to fully satisfy the kiln thermal energy demand, shows that 191.7 thousand tonnes of bituminous $A$ coal is to be burned annually resulting in $\sim 525.7$ thousand tonnes of $\mathrm{CO}_{2}$ released to the atmosphere. In addition to fuel cost, over $\$ 21$ million of carbon tax are to be added to the overall cost of operation.

In scenario II, an additional capital cost of around $\$ 12$ million is estimated for the retrofitting for NG pipeline. The total recurring cost of fuel to the kiln increases by $28 \%$ from scenario I. However, with the addition of carbon tax of CAD $\$ 50$ per tonne of $\mathrm{CO}_{2}$, the total recurring cost of fuel in Scenario II is $3.7 \%$ less than that of Scenario I and is further reduced by $24 \%$ when adopting Canada's 2030 carbon tax of CAD $\$ 170$ per tonne of $\mathrm{CO}_{2}$. The pay back in this scenario is estimated to be $\$ 698,000$ with the assumption of $2.5 \%$ interest rate and a payback period of 30 years. Considering the total capital cost of pipeline retrofitting and the hydrogen plant, a capital payback of $\$ 1.48$ million is estimated for scenario III at $2.5 \%$ interest rate and 30 years payback period.

Figures 2 and 3 provide a comparative assessment on the outcomes of analyzing the three different scenarios. $\mathrm{CO}_{2}$ emissions from all scenarios are shown in Fig. 2. One can see that the reduction in total fuel cost in scenario II comes with $43.3 \%$ reduction in $\mathrm{CO}_{2}$ emissions. It also shows that $\mathrm{CO}_{2}$ emission is reduced in scenario III by $\sim 0.4 \%$ and $43.5 \%$ with respect to scenario I and II, respectively. In scenario III, the utilization of oxygen produced from the hydrogen plant in fuel combustion is not considered. Increasing oxygen concentration in the kiln's combustion air to $25 \%$ can result in around $9 \%$ reduction in fuel consumption and emissions. A comparative assessment of the three scenarios is provided in Fig. 3 without the inclusion of the capital cost and its effect on the scenarios. This figure only compares the total cost of consumed fuels, cost of carbon taxes, and the total recurring cost including cost of running the hydrogen plant with consideration of the revenue from hydrogen sales of scenario III.

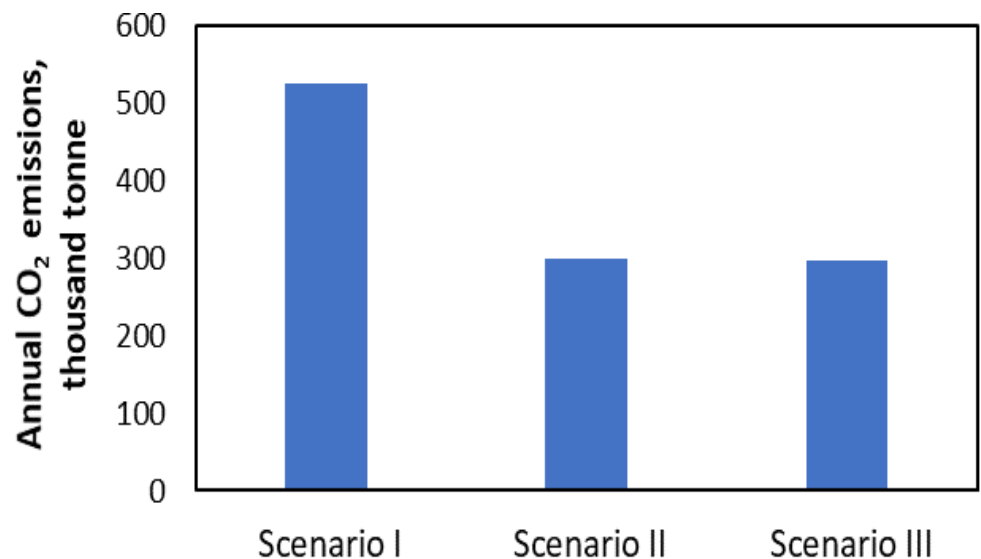

Fig. 2: Emissions from the cement kiln only at the different considered scenarios 


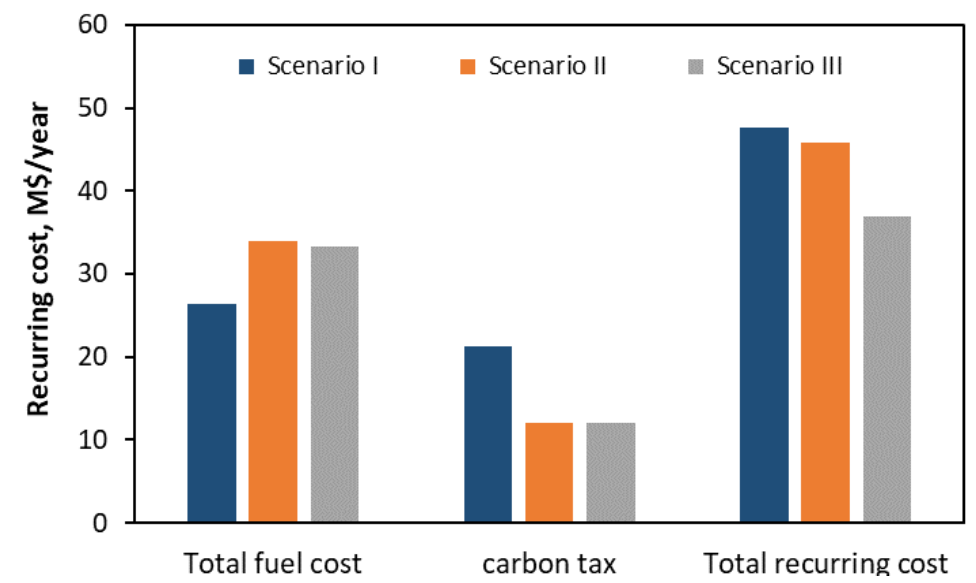

Fig. 3: Comparative assessment of the recurring cost of the different scenario

\section{Conclusion}

This case study provided an insight into the huge potential of offsetting carbon emissions in a typical cement production plant by incorporating several scenarios including replacing coal with NG alone or NG enriched with Hydrogen. The hydrogen could be produced on-site using an innovative thermos-chemical cycle that runs on the waste heat from the plant. Comparative analysis of the three scenarios was performed with the necessary retrofitting to provide large stream of natural gas and deployment of the hydrogen plant. The study shows that with large-scale on-site hydrogen production, the recurring cost of operating the kiln and associated carbon emissions can be reduced through the use of low-carbon (i.e. natural gas) or carbon-free (i.e. hydrogen) fuels to meet a considerable portion of the energy to run the cement plant. A reduction of over $43 \%$ in $\mathrm{CO}_{2}$ emissions and associated carbon tax was achieved by introducing hydrogen-enriched natural gas to the kiln. This is reflected on the total recurring cost of the kiln fuel which is reduced by $5.14 \%$. While around 1.8 tonnes of the on-site produced hydrogen are utilized in the cement plant, the rest of the plant capacity can bring in revenue of over $\$ 11$ million. The revenue of the system can be increased when the highly demanded pure oxygen is sold to industrial or medical sectors.

\section{References}

[1] J. Olivier, G. Janssens-Maenhout, M. Muntean, and J. Peters, "Trends in global CO2 emissions: 2016 Report," PBL Netherlands Environmental Assessment Agency, 2016.

[2] J. Lehne and F. Preston, "Making Concrete Change: Innovation in Low-carbon Cement and Concrete," 2018.

[3] M. J. S. Zuberi and M. K. Patel, "Bottom-up analysis of energy efficiency improvement and CO2 emission reduction potentials in the Swiss cement industry," Journal of Cleaner Production, vol. 142, pp. 4294-4309, 2017, doi: 10.1016/j.jclepro.2016.11.178.

[4] N. A. Madlool, R. Saidur, M. S. Hossain, and N. A. Rahim, "A critical review on energy use and savings in the cement industries," Renewable and Sustainable Energy Reviews, vol. 15, no. 4, pp. 2042-2060, 2011, doi: 10.1016/j.rser.2011.01.005.

[5] N. A. Madlool, R. Saidur, N. A. Rahim, M. R. Islam, and M. S. Hossian, "An exergy analysis for cement industries: An overview," Renewable and Sustainable Energy Reviews, vol. 16, no. 1, pp. 921-932, 2012, doi: 10.1016/j.rser.2011.09.013.

[6] M. D. Obrist, R. Kannan, T. J. Schmidt, and T. Kober, "Decarbonization pathways of the Swiss cement industry towards net zero emissions," Journal of Cleaner Production, vol. 288, 2021, doi: 10.1016/j.jclepro.2020.125413.

[7] Z. Söğüt, Z. Oktay, and H. Karakoç, "Mathematical modeling of heat recovery from a rotary kiln," Applied Thermal Engineering, vol. 30, no. 8-9, pp. 817-825, 2010, doi: 10.1016/j.applthermaleng.2009.12.009.

[8] R. S. El-Emam and I. Khamis, "Advances in nuclear hydrogen production: Results from an IAEA international collaborative research project," International Journal of Hydrogen Energy, vol. 44, no. 35, pp. 19080-19088, 2019, doi: 10.1016/j.ijhydene.2018.04.012. 